\title{
Consultório na Rua: experiências e sentimentos vivenciados pelos profissionais na assistência em saúde
}

\author{
John Victor dos Santos Silva ${ }^{(\mathbb{D})}$, Claudio José dos Santos Júnior ${ }^{2} \mathbb{( D}$, Waldez Cavalcante Bezerra ${ }^{3} \mathbb{( D )}$,
} Thyara Maia Brandão4 (D)

\begin{abstract}
RESUMO
Introdução: o Consultório na Rua é uma estratégia da Atenção Básica no Sistema Único de Saúde (SUS), que tem como finalidade promover o cuidado às pessoas em situação de rua, sendo o serviço de referência sanitária para esta população. Através de ações que permitam a construção do vínculo de confiança, os profissionais promovem cuidado e assistência de saúde às demandas dos usuários. Objetivo: descrever as experiências, histórias e sentimentos vivenciados pelos profissionais do Consultório na Rua de Maceió-AL. Métodos: trata-se de estudo descritivo-exploratório, com abordagem qualitativa, realizado com 13 profissionais do Consultório na Rua de Maceió, cuja produção de dados ocorreu no período de outubro a dezembro de 2018, através da técnica da entrevista semiestruturada e dos registros em diário de campo. Os dados foram analisados pela técnica da Análise de Conteúdo, na modalidade temática, e discutidos à luz da literatura sobre a temática do Consultório na Rua. Resultados: a partir das entrevistas com os profissionais emergiram as seguintes temáticas: 1) experiências únicas; 2) histórias que marcam; e 3) sentimentos que transformam. Conclusão: pode-se concluir que o Consultório na Rua se mostra como um trabalho que gera ricas experiências e sentimentos para os profissionais, e que permite que os profissionais conheçam as histórias de vida dessa população ao mesmo tempo em que são afetados nesse processo.
\end{abstract}

Palavras-chave: Serviços básicos de saúde, Prestadores de cuidados de saúde, Humanização da assistência, Pessoas em situação de rua, Pesquisa qualitativa.

1. Universidade de São Paulo (USP). Escola de Enfermagem de Ribeirão Preto. Programa de Pós-Graduação em Enfermagem Psiquiátrica, Ribeirão Preto (SP), Brasil

2. Universidade Estadual de Ciências de Alagoas (UNCISAL). Centro de Ciências da Saúde, Curso de Medicina. Maceió (AL), Brasil 3. Universidade Estadual de Ciências da Saúde de Alagoas (UNCISAL). Centro de Ciências da Saúde, Curso de Terapia Ocupacional. Maceió ( $A L)$, Brasil

4. Universidade Estadual de Ciências da Saúde de Alagoas (UNCISAL). Centro de Ciências da Saúde, Curso de Enfermagem. Maceió (AL), Brasil 


\section{INTRODUÇÃO}

As pessoas em situação de rua vivem um complexo processo de vulnerabilização decorrente das desigualdades estruturais da sociedade capitalista, de modo que uma série de rupturas e fragilidades econômicas, sociais, culturais e relacionais incidem na vida dessas pessoas antes mesmo da ida para a rua como local de moradia. Esse processo é cercado de preconceitos e estigmatizações que precisam ser trabalhados para que seja possível conhecer as particularidades que envolvem o "viver na rua", de maneira que seja possível diminuir ao máximo as diferenças que existem entre as pessoas que estão em situação de rua e os demais cidadãos, principalmente no acesso às políticas de assistência social, educação e saúde ${ }^{1}$.

No que diz respeito ao acesso às políticas sociais, e, especificamente, ao cuidado em saúde, por muitos anos as pessoas em situação de rua permaneceram às margens, sem nenhuma garantia ou direito ao acesso de forma universal à toda a rede assistencial, limitadas apenas, quando aceitas nos serviços para oferta de assistência, aos atendimentos de urgência ou emergência².

As pessoas em situação de rua sofrem com o preconceito e estigma social que sua condição provoca, tanto por parte dos profissionais de saúde, como dos demais usuários dos serviços, seja na atenção básica ou nos serviços especializados e hospitalares, sendo-lhes, frequentemente, negado qualquer tipo de assistência².

Diante do contexto de precarização das formas de inserção e participação desse grupo social e da sua exclusão de acesso aos bens e serviços sanitários e sociais, houve, ao longo dos anos, grande movimento social e político no setor da saúde, visando assegurar que as pessoas em situação de rua ganhassem espaço e tivessem seus direitos garantidos através do Sistema Único de Saúde (SUS). Assim, surgiram diversas estratégias que foram modelo e caminhos ao que culminou com a instituição do serviço designado, em 2011, como Consultório na Rua, serviço destinado à Atenção Básica/Atenção Primária à Saúde da população que vive em situação de rua no território brasileiro ${ }^{3}$.

O Consultório na Rua é uma estratégia do SUS, integrante da Política Nacional da Atenção Básica (PNAB) e que trabalha de forma dinâmica, em diversos cenários das cidades, através da busca ativa pelas pessoas em situação de rua no intuito de ofertar uma assistência integral baseada em suas necessidades em saúde, livre de preconceitos ou julgamentos ${ }^{4}$. Por ser a população em situação de rua um grupo bastante heterogêneo, com necessidades e características bem específicas, o Consultório na Rua, para o atendimento desse público organiza-se em equipes multiprofissionais, trabalhando de forma itinerante, em locais e horários distintos, dentro do seu território de atuação ${ }^{4}$.

Os profissionais que atuam no Consultório na Rua realizam o seu processo de trabalho nas áreas externas, como praças, parques, terrenos baldios, prédios invadidos e calçadas, utilizando, em alguns momentos, o ambiente e recursos das unidades de saúde a que estão vinculados, serviços especializados, unidades de emergência e hospitalares, principalmente quando as pessoas em situação de sua precisam de um atendimento mais completo. No entanto, é na rua que a maior parte da assistência em saúde acontece, sendo realizados os mais diversos procedimentos, como prénatal, curativos, atendimento odontológico e atividades educativas, entre outros ${ }^{4,5}$.

Assim, o trabalho com a população em situação de rua pode trazer aos profissionais, experiências diferentes do trabalho convencional em serviços fechados como as unidades de saúde, os hospitais e os consultórios. As interações com as pessoas em situação de rua e com suas histórias de vida podem trazer aos profissionais ricas experiências sobre trajetórias de vida marcadas por vulnerabilidades diversas que envolvem o viver na rua, provocando os mais diversos sentimentos nos trabalhadores que cuidam desse grupo ${ }^{6}$.

Desta forma, o objetivo do presente estudo foi conhecer as histórias, experiências, e sentimentos vivenciados pelos profissionais do Consultório na Rua durante o trabalho com seus usuários.

\section{MÉTODO}

Trata-se de um estudo descritivo-exploratório, com abordagem qualitativa. Esta abordagem, em sua essência, permite, através das percepções dos entrevistados, dos sentidos e significados atribuídos por eles sobre o vivido, uma investigação das singularidades e subjetividades experimentadas. Identifica-se com os estudos exploratórios, bastante utilizados quando se deseja conhecer o objeto de estudo exatamente como ele se apresenta dentro do seu contexto, na sua realidade e perspectiva? ${ }^{7}$. 
Participaram 13 profissionais do Consultório na Rua de Maceió-AL, através da técnica de amostragem por saturação ${ }^{8}$, frequentemente utilizada na pesquisa qualitativa em saúde e que aponta a interrupção de inclusão de novos participantes quando as informações, experiências e vivências se tornam redundantes e repetitivas, não trazendo novos significados.

Foram incluídos os profissionais das equipes do Consultório na Rua que atuavam na assistência direta às pessoas em situação de rua e excluídos aqueles que estavam em qualquer tipo de licença médica ou afastamento. Todos consentiram em participar deste estudo, após apresentação, explicação, entrega e assinatura do Termo de Consentimento Livre e Esclarecido (TCLE) pelos participantes e pesquisadores.

Os cenários onde o estudo aconteceu foram as unidades de saúde de apoio onde os profissionais se reúnem para o trabalho.

Inicialmente, os pesquisadores entraram em contato com a coordenação geral do Consultório na Rua de Maceió-AL, que, logo em seguida, disponibilizou o contato telefônico de cada um dos líderes das equipes para agendamento das visitas e entrevistas nas unidades, em dia e horário pré-estabelecidos. Cada um dos participantes foi convidado em dias, horários e locais distintos, mas sempre no período de trabalho, para diminuir ao máximo o desconforto e possibilitar a imersão no contexto em que as experiências, sentidos e histórias acontecem.

A produção dos dados ocorreu entre outubro e dezembro de 2018 por meio da técnica de entrevista semiestruturada, sendo esta orientada por um roteiro previamente elaborado, contendo 15 questões abertas referentes aos objetivos específicos da pesquisa. Houve gravação das entrevistas em áudio, com duração média de 40 minutos, autorizadas pelos participantes, e feitas anotações em diário de campo para registro das particularidades da entrevista. As entrevistas foram transcritas na íntegra, recebendo cada participante como código o nome "colaborador", seguindo de um número, distribuídos na ordem cronológica em que as entrevistas foram realizadas.

A análise dos dados aconteceu através da técnica de Análise de Conteúdo, na modalidade temática ${ }^{7}$, que permite uma exploração minuciosa dos materiais, a fim de encontrar os significados através dos núcleos de sentido das falas. Essa análise aconteceu em três etapas, de acordo com a técnica: 1) pré-análise: onde acontece uma leitura flutuante de todo o material produzido, no intuito de uma maior aproximação com dados e iniciar a construção dos significados; 2) exploração do material: nessa etapa começa a estratificação das unidades das falas, agrupamentos dos núcleos e atribuição de temas; 3) tratamento dos dados e interpretação: agrupamento dos núcleos temáticos, construção dos resultados e interpretação de acordo com os significados apresentados pelos núcleos ${ }^{7}$.

O estudo seguiu todos os preceitos éticos estabelecidos pelo Conselho Nacional de Saúde, através da resolução n. ${ }^{\circ}$ 510/2016, contando com a autorização da Secretaria Municipal de Saúde e da coordenação das equipes do Consultório na Rua de Maceió, sendo submetido ao Comitê de Ética em Pesquisa (CEP), e autorizado através do protocolo de parecer n. ${ }^{\circ}$ 2.737.153 e CAEE n. ${ }^{\circ}$ 90815118.5.0000.5011.

\section{RESULTADOS E DISCUSSÃO}

Dos 13 profissionais que participaram desta pesquisa, oito eram do gênero feminino e cinco do gênero masculino. Todos tinham idades entre $22 \mathrm{e}$ 35 anos. Sobre a formação e categoria profissional, sete eram profissionais de nível superior (duas enfermeiras, duas assistentes sociais, uma psicóloga, um educador físico e um terapeuta ocupacional), seis de nível médio (dois técnicos em enfermagem e quatro redutores de danos). Sobre o tempo de trabalho no Consultório na Rua, um dos profissionais estava atuando há menos seis meses e os demais há mais de um ano.

Através da produção e análise dos dados foram estabelecidos os seguintes eixos temáticos para apresentação e discussão dos resultados: 1) Experiências únicas, 2) Histórias que marcam; e 3) Sentimentos que transformam. Os eixos e resultados encontrados foram discutidos à luz da literatura científica atual sobre a temática.

\section{Eixo temático 1: Experiências únicas}

A assistência em saúde promovida pelas equipes da estratégia Consultório na Rua apresenta condições diferentes dos demais serviços da rede de atenção à saúde. Destinada à assistência das pessoas em situação de rua na cidade, os profissionais se deparam com as mais diversas situações, realizando o trabalho, desde 
orientações até os atendimentos médico, odontológico e psicológico, além de curativos, vacinas e coleta de material para exame de laboratório ou testes rápidos, entre outras condutas aplicáveis caso a caso, sempre no cenário onde os indivíduos se encontram, seja uma praça, sejam as esquinas ${ }^{4}$. Para identificar a estratégia de atendimento, o primeiro passo é a abordagem, uma aproximação em busca da construção de um laço de amizade ou vínculo afetivo, somente então se elabora um projeto singular de atendimento ou cobertura assistencial.

O Consultório na Rua, como componente da Atenção Básica, desenvolve o mesmo trabalho que os profissionais das Unidades Básicas de Saúde (UBS), porém no local onde a pessoa em situação de rua se encontra. Atividades que são realizadas em ambientes com salas de espera e consultório, com certa comodidade e conforto, precisam ser improvisadas em ruas, calçadas, bancos de praça, juntamente com todo movimento e sonorização de uma cidade e sociedade em constante movimento e rotatividade de pessoas, com o mínimo de privacidade9.

A realização da assistência nessas diversas condições foi um desafio para os profissionais entrevistados, apresentando-se para eles como experiências únicas, nunca vivenciadas em outros serviços de saúde em que atuaram ao longo da carreira profissional e que só esse trabalho proporcionaria, principalmente tratando-se das condições mínimas para o cuidado e a segurança na assistência em saúde ${ }^{10}$, como aconteceu em nossa realidade:

Nunca esqueço a primeira vez que eu atendi uma gestante na rua. Eu nunca imaginei como seria acompanhar um pré-natal no meio da rua até estar fazendo isso. É o que a gente faz! A gente tem que atender no meio da rua e com a mesma qualidade como se fosse dentro do consultório, só que na rua, às vezes no sol, né, numa praça. Foi uma experiência única e que eu só viveria se eu estivesse trabalhando aqui, né. (Colaboradora 2, Enfermeira).

Apesar das equipes contarem com o apoio de unidades de saúde de referência para o atendimento, nem sempre é possível deslocar o usuário até elas, mesmo em condições que justificariam tal conduta, quando, por exemplo, existe a necessidade de uma consulta ou procedimento mais completo. Contudo, mesmo em situações deste tipo, ainda assim há uma resistência significativa por parte das pessoas em situação de rua em aceitar a ida até as unidades, motivo pelo qual a assistência precisa ser realizada no local.
Eu me lembro de uma vez que um homem, um senhor, estava com uma ferida muito feia, bem feia mesmo, no pé, e a gente queria que ele fosse com a gente para a unidade, porque teríamos mais materiais lá, mas ele não quis ir de jeito nenhum, então o pessoal teve que fazer ali mesmo, e com os materiais que tínhamos, e eu ajudei como eu pude, com as coisas que a gente tinha lá, por isso que a gente tem que andar com o máximo de material possível, porque é isso que vai acontecer, a gente vai ter que cuidar deles lá. (Colaboradora 7, Redutora de danos).

A resistência apresentada por esses indivíduos pode ser consequência de diversos aspectos sociais e humanos. Um deles está relacionado ao pertencimento ao mundo da rua. Sair do local onde se encontra e se deslocar até uma unidade de saúde pode significar a perda daquele território conquistado e que é sua referência, além do risco daqueles pertences que não possa carregar consigo ${ }^{9}$. Outro aspecto refere-se ao tipo de relação e experiências previamente vividas junto aos serviços de saúde, que podem ter sido de impessoalidade, rechaço ou maus tratos.

$O$ estudo de Bezerra et al. ${ }^{11}$ revelou que os processos de exclusão, violência e discriminação sofridos pelas pessoas em situação de rua ocorrem de diversos modos e em diferentes espaços, inclusive naqueles destinados ao acolhimento e cuidado em saúde. Silva ${ }^{12}$ destaca que além de terem sido historicamente alijadas do acesso à saúde, quando adentram aos serviços de saúde se deparam com o preconceito e a falta de capacitação dos profissionais para atenderem às suas especificidades, além de terem que lidar com vários entraves burocráticos, como o fato de não possuírem endereço domiciliar, documento de identificação, cartão SUS e outros documentos exigidos no atendimento ou marcação de consultas, entre outros ${ }^{13}$.

Vê-se, então, que o cuidado é feito, principalmente, no território das ruas. As equipes procuram estar sempre equipadas com todos os materiais e recursos necessários para o trabalho, deslocando-se com um carro de apoio da secretaria de saúde para seus locais de atuação. As equipes, compostas por profissionais de diversas formações e níveis de escolaridade, atuavam em conjunto para uma assistência mais ampla e integral para os indivíduos que estão na rua, procurando ao máximo atuar de acordo com suas necessidades, sem reproduzir as violências e preconceitos institucionais ${ }^{13}$. 
O trabalho em conjunto, em equipe, é uma marca muito forte deste tipo de serviço, "nunca vivida antes":

Olhe, o que a gente faz aqui é diferente do que se faz em outros lugares, viu, a gente é uma equipe mesmo aqui, a gente se ajuda, a gente coopera demais um com o outro aqui para poder fazer nosso trabalho da melhor forma. Se um vai fazer um curativo, o outro segura o material; se um vai fazer um atendimento com a gestante, os outros ficam fazendo uma atividade com os outros filhos dela; uns participam da atividade enquanto outros distribuem a água. A cooperação aqui é muito grande, eu mesmo nunca vi isso em outro lugar. (Colaborador 1, Redutor de danos).

Essas experiências relatam as particularidades do trabalho e da assistência no Consultório na Rua, em muitos aspectos tão diferentes daquele trabalho e assistência que ocorre nos demais serviços de saúde que compõem a rede, seja pelas especificidades do público ou pelas condições e a forma como o trabalho é realizado, o que, do ponto de vista destes profissionais, tornam o trabalho único.

\section{Eixo temático 2: Histórias que marcam}

Outro aspecto bastante evidenciado nas falas dos profissionais do Consultório na Rua são as histórias de vida das pessoas que estão em situação de rua. Em meio ao trabalho, em contato com essas pessoas, os profissionais vão conhecendo mais sobre as trajetórias de vida e os cotidianos delas, o que envolve suas rotinas e os motivos que as fizeram ir para as ruas como refúgio e lar.

A singularidade de cada história não somente marca os profissionais das equipes dos Consultórios na Rua, principalmente quando eles conseguem estabelecer vínculo afetivo com esses moradores, também revela os diferentes motivos da ida para a rua, associados com situações diversas, mas que promoveram rupturas relacionais no âmbito familiar, doméstico ou comunitário.

Cada um tem uma história diferente. Tem gente que perdeu vínculo com a família por causa da bebida, o outro tirou a vida do irmão e teve que sair correndo da família, outro sofria violência em casa, são tantas coisas. Tem muitas coisas! Cada cidadão que vive em situação de rua tem uma verdadeira história de tá ali, né. E a gente acaba conhecendo, mas para eles se abrirem assim para gente, às vezes leva tempo. (Colaboradora 2, Enfermeira).
A Pesquisa Nacional sobre População em Situação de Rua ${ }^{14}$, primeiro censo que buscou conhecer as características dessa população em âmbito nacional, realizada em 2009, evidenciou que os principais motivos pelos quais as pessoas passaram a viver e morar na rua se referiam "aos problemas de alcoolismo e/ou drogas (35,5\%); desemprego $(29,8 \%)$ e desavenças com familiares $(29,1 \%)^{\prime \prime 14}$. Bezerra et al. ${ }^{11}$ também constataram que a fragilidade e/ou ruptura dos laços de pertencimento no âmbito da família, por motivos diversos, são frequentes nas trajetórias de vida dessas pessoas, sendo uma das principais razões do adentrar a situação de rua.

Nota-se, também, que o acesso a essas histórias, como um aspecto importante para pensar a assistência junto à pessoa em situação de rua, é facilitado pela construção do vínculo entre profissional e morador. As pessoas que estão em situação de rua tendem a ser banalizadas, hostilizadas e sofrerem todo tipo de preconceito e violência por parte da sociedade, desta maneira, como forma de proteção, elas evitam a aproximação e o contato, pois são cercados pelo medo, pela insegurança e, principalmente, por um forte senso de sobrevivência e autoproteção, inclusive, por causa das várias formas de violência sofridas. Assim, construir a confiança é algo necessário para que seja possível oferecer $\mathrm{o}$ atendimento, ajuda e cuidado ${ }^{15}$.

Quando esta vinculação é estabelecida, os profissionais conseguem compreender e conhecer mais sobre a particularidade desse segmento social. As histórias de vida vão sendo compartilhadas entre o profissional e o sujeito, fazendo com que eles estabeleçam também, além da confiança, vínculos afetivos, de tal forma que essas pessoas passam a enxergar os profissionais como parte de uma limitada rede pessoal de suporte, como indivíduos que eles podem contar em variadas as situações, como podemos perceber nessa história contada pelo Colaborador 12:

Teve um jovem de quatorze anos que eu acompanhava, eu era o Técnico de Referência dele no centro e ele levou uma facada no coração e quando chegou no HGE [Hospital Geral do Estado] o primeiro nome que ele deu para o pessoal, para chamar, foi o meu. Então eles foram tentar localizar quem era a Rosa [nome fictício] e descobriram que Rosa era do Consultório na Rua e eu passei quatorze dias indo de manhã e de tarde lá, visitar e ficar com ele e quando 
ele acordou do coma ele dizia que lembrava de mim, muito. Nossa! Isso foi muito marcante para mim, porque ele lembrou de alguém que cuidava dele e era eu. (Colaboradora 12, Assistente Social).

Essas histórias permitem que os profissionais desfaçam preconceitos sobre os motivos que levam uma pessoa a procurar a rua como refúgio, e conhecendo esses motivos e histórias individuais, eles começam a compreender algumas atitudes que as pessoas em situação de rua tomam no dia a dia, como medidas de se proteger de pessoas ou situações que possam apresentar risco para elas.

Uma vez a gente encontrou uma travesti. Ela estava toda machucada, várias marcas, e a gente a encontrou dentro do lixo, né. Ela estava toda maltratada mesmo. A gente acolheu, fez o necessário e, em outro dia, a gente encontrou com ela novamente e eu pude perguntar por quê que ela estava no lixo, né, e ela disse que estava dentro do lixo por que ela era da cor do saco do lixo e, assim, ninguém conseguia ver e ela poderia ficar protegida. Foi aí que eu pude entender, sabe? Algumas coisas que eles fazem, eles fazem para se proteger. (Colaboradora 10, Enfermeira).

Cada história, cada pessoa que recebe o atendimento das equipes do Consultório na Rua, permite que esses profissionais percebam que as condições de saúde são de fato multifatoriais ${ }^{10}$. As pessoas em situação de rua, mesmo com todas as dificuldades que o viver na rua implica, tentam sobreviver, não apenas às condições como falta de cuidados básicos de saúde e de higiene, mas, também, às situações de violência a que estão expostos cotidianamente, além da falta de segurança, de alimentação adequada e de água, tanto para beber como para a higiene pessoal, entre outros aspectos, que são considerados primordiais para a vida humana ${ }^{11,13,16}$.

Mesmo diante de situações adversas, é possível refletir que o trabalho das equipes do Consultório na Rua faz uma diferença importante na vida das pessoas que estão recebendo o cuidado e a atenção por parte desses profissionais ${ }^{17}$. Desta forma, a complexidade das necessidades e demandas das pessoas em situação de rua extrapolam as especificidades do setor da saúde e impõem às equipes do Consultório na Rua o desafio da articulação intersetorial. Assim, articuladas com outros setores de políticas sociais, como educação, assistência social, seguridade social, as equipes buscam acionar outros serviços e profissionais para possibilitar uma assistência mais ampla para esses sujeitos, pensando na sua reintegração social a partir do engajamento em atividades que possibilitem a aquisição e o exercício de novos e diferentes papéis sociais.

Eu fiquei muito feliz quando, um dia, passando pelo bairro (...) encontrei aquela travesti que a gente cuidou, que a gente encontrou no lixo, toda machucada, ela estava trabalhando no salão de beleza. Eu passei por ela, falei com ela. É muito bom ver a mudança na vida das pessoas. A gente passou mais ou menos um mês indo lá onde ela ficava, cuidando, orientando, ajudando como a gente pode, dando conselhos. E hoje ela está bem, trabalhando, isso é muito bom. (Colaboradora 10, Enfermeira)

Observa-se, a partir dos relatos, que os profissionais, para além do cuidado específico de saúde, tornam-se, também, agentes de mudança da realidade de vida desses sujeitos ao facilitar um acesso mínimo aos direitos e serviços sociais, que pode fornecer o suporte para que eles consigam encontrar meios de melhorar a própria vida.

\section{Eixotemático 3: Sentimentos que transformam}

A partir do que foi discutido até este momento, constata-se que o trabalho no Consultório na Rua é permeado de sentimentos que surgem ou são potencializados através das experiências, do contato com as histórias de vida, das situações singulares e transformadoras vivenciadas pelos profissionais. Um sentimento bastante evidente na maioria das falas dos profissionais é o de tristeza em relação às inúmeras vulnerabilidades e rupturas que marcaram a vida das pessoas em situação de rua e sua condição atual.

Nossa! O sentimento de tristeza, tá ligado? Acredito que todos aqui já passaram por uma situação que ficou muito triste, pela situação da pessoa mesmo. A gente tá aqui trabalhando sempre, mas a gente nunca se acostuma com essa situação, por isso a gente dá tudo de si pra fazer o melhor que pode para ajudar as pessoas dentro do que a gente pode fazer no trabalho, né, para não estar levando isso para casa, mas é muito triste ver a que ponto a pessoa chegou, né. (Colaborador 8 , Redutor de danos)

Não só o viver na rua traz o rompimento dos vínculos familiares e sociais, mas o rompimento destes também pode fazer com que a pessoa tenha o viver na rua como única possibilidade. $O$ desemprego, as vivências de inadequação e as dificuldades de superar sofrimentos emocionais 
também podem levar a pessoa a morar na rua. Essas condições favorecem a que o sujeito viva na condição de desfiliação social, caracterizada pela ausência de relações significativas nos dois principais eixos da inserção social: o mundo do trabalho e o das relações interpessoais ${ }^{18,19}$.

Assim, a tristeza sentida pelos profissionais está relacionada com o fato de verem um ser humano em estado mais subjugado, de abandonado, e/ou desfiliação pela família, pela comunidade e sociedade em geral, frequentemente à margem até mesmo da esfera do serviço público, da proteção social estatal, o que dificulta as possibilidades de mudança em suas trajetórias de vida. $O$ isolamento social se apresenta até mesmo nos momentos finais da vida dessas pessoas, na própria morte, tendo a equipe que assumir o papel que seria dos entes familiares ${ }^{20,21}$.

Eu lembro de uma senhora que a gente acompanhou, ela dizia que tinha sido abandonada pela família, né. Ela dizia que a família não a queria de jeito nenhum e a gente tentou encontrar a família, a gente até conseguiu encontrar, e viu que a família não queria mesmo ela perto, sabe. Isso é muito triste. Ela foi piorando, piorando, porque ela carregava toda essa tristeza. E ela chegou a falecer, a gente até falou para família, mas a família não foi, então foi a gente da equipe que ficou lá no enterro dela. (Colaborador 9, Terapeuta Ocupacional).

Esse sentimento de abandono é percebido pelos profissionais como consequência das situações de vida que foram escolhidas ou impostas às pessoas em situação de rua, que nem sempre estiveram nessas condições, fazendo esquecer suas histórias e trajetórias de vida. $O$ abandono é algo bastante evidente nas histórias dessas pessoas, as quais contam fatos da sua vida enquanto os profissionais prestam assistência e cuidado. Essas narrativas revelam um sentimento de que foram esquecidas, tanto pela família, como pela própria sociedade ${ }^{20}$.

A tristeza em ver as pessoas em situação de rua em condição de vulnerabilidade extrema dispara reflexões entre os profissionais do Consultório na Rua sobre suas próprias vidas, suas relações afetivas, familiares e de trabalho ${ }^{18}$. Assim, diante da realidade dos usuários, alguns profissionais passam a questionar suas próprias atitudes e posições diante da vida.

Olhe, teve esse senhor, sabe? Mexeu muito comigo. Ele tinha filho médico, advogado. Os filhos iam lá onde ele estava, pedia pra ele voltar para casa, mas ele não voltava, dizia que tinha feito algo de errado e não podia voltar. Nem mesmo os filhos sabiam o que ele tinha feito, mas diziam que perdoava ele, mas ele não queria voltar de jeito nenhum. Depois dele, sabe? De conhecer ele, eu comecei a refletir sobre tudo na minha vida. Tem coisas que não valem a pena, sabe? Às vezes a gente se afasta de um familiar por uma besteira, mas depois a gente vê o valor da família, das coisas simples, o valor da vida, sabe? (Colaborador 4, Educador Físico).

Esse sentimento de que a vida tem outro valor é bastante presente na fala dos profissionais que estão no Consultório na Rua. Eles expressam que começaram a olhar a vida com outra perspectiva, principalmente quando é percebido que pessoas em situação de rua também sorriem, brincam, aparentam estar felizes, mesmo em meio a tantas vulnerabilidades e motivos para sentirem 0 contrário 22 .

Os profissionais relatam que as pessoas que estão em situação de rua demostram muita gratidão e carinho pelo trabalho e pelas equipes, por todo cuidado que recebem, mesmo que aquele cuidado seja parte da função do trabalho, eles entendem que se não fosse por eles, não seriam vistos e nem receberiam qualquer tipo de assistência.

Eles agradecem muito a gente. São muito gratos, né. Eu digo que é o meu trabalho, que eu tenho que fazer isso, mas mesmo assim a forma como eles olham para gente, como eles agradecem, eu sinto que estou fazendo de verdade a diferença na vida de alguém, né. E quando eu vejo eles sorrindo, mesmo não tento nada, mesmo com a situação, eles sorriem, eles brincam. É muito gratificante! (Colaborador 1, Psicóloga).

Todas essas experiências, essas histórias de vida e sentimentos relatados pelos profissionais do Consultório na Rua mostram que o cuidar das pessoas em situação de rua acarreta desafios e aprendizados constantes, desde a forma de organizar e realizar o trabalho até o modo de perceber a vida, através de outras perspectivas.

\section{CONSIDERAÇÕES FINAIS}

Este estudo procurou descrever, na perspectiva de quem trabalha no Consultório na Rua, algumas das experiências vividas e os sentimentos provocados pelas mais diversas circunstâncias que esse trabalho proporciona, além do compartilhamento de histórias de vida das pessoas em situação de rua que marcam 
os profissionais desse âmbito da atenção à saúde. As características dos usuários, do processo de trabalho, das experiências e dos sentidos do trabalho, mostram-se diferentes dos demais serviços de produção de saúde, haja vista que o deslocamento dos espaços tradicionais de assistência para o ambiente da rua como local de trabalho, com todas as peculiaridades que isso envolve.

Embora traga ricos relatos, este estudo limitouse a descrever a percepção de profissionais das equipes de Consultório na Rua de uma capital do Nordeste do Brasil, podendo apresentar experiências e vivências diferentes das encontradas em equipes de outras cidades e regiões. Assim, sugere-se que novos estudos sejam feitos para conhecer mais sobre as singularidades do trabalho das equipes de Consultório na Rua e de como este afeta os profissionais e também as próprias pessoas em situação de rua.

\section{REFERÊNCIAS}

1. Mendes KT, Ronzani TM, Paiva FS, Mendes KT, Ronzani TM, Paiva FS. População em situação de rua, vulnerabilidades e drogas: uma revisão sistemática. Psicol Soc [Internet]. 2019;31:1-15. Disponível em: http://dx.doi.org/10.1590/1807-0310/2019v31169056.

2. Rosa AS, Santana CLA. Street Clinic as good practice in Collective Health. Rev Bras Enferm. [Internet]. 2018;71:465-6. Disponível em: http://dx.doi. org/10.1590/0034-7167-201871sup102.

3. Ferreira CPS, Rozendo CA, Melo GB. Consultório na rua em uma capital do nordeste brasileiro: o olhar de pessoas em situação de vulnerabilidade social. Cad Saude Publica [Internet]. 2016;32(8):1-10. Disponível em: http://dx.doi.org/10.1590/0102-311X00070515.

4. Timóteo AVG, Silva JVS, Gomes LKG, Alves ASS, Barbosa VMS, et al. Caracterização do trabalho e ações desenvolvidas pelas equipes do Consultório na Rua de Maceió - AL. Enferm em Foco [Internet]. 2020;11(1):126130. Disponível em: https://doi.org/10.21675/2357707X.2020.v11.n1.2757.

5. Simões TRBA, Couto MCV, Miranda L, Delgado PGG. Missão e efetividade dos Consultórios na Rua: uma experiência de produção de consenso. Saúde debate [Internet]. 2017;41(114):963-75. Disponível em: https://doi.org/10.1590/0103-1104201711423.

6. Paula HC, Daher DV, Koopmans FF, Faria MGA, Brandão PS, Scoralick GBF. Implementation of the Street Outreach Office in the perspective of health care. Rev Bras Enferm [Internet]. 2018;71:2843-1847. Disponível em: http://dx.doi.org/10.1590/0034-7167-2017-0616.

7. Minayo MCS. O desafio do conhecimento: pesquisa qualitativa em saúde. 14. ed. São Paulo: Hucitec; 2014.
8. Minayo MCS. Amostragem e saturação em pesquisa qualitativa: consensos e controvérsias. Rev Pesqui Qual [Internet]. 2017;5(7):1-12. Disponível em: https://editora.sepq.org.br/index.php/rpq/article/ view/82/59

9. Vargas ER, Macerata I. Contribuições das equipes de Consultório na Rua para o cuidado e a gestão da atenção básica. Rev Panam Salud Pública [Internet]. 2018;42:e170. Disponível em: https://doi.org/10.26633/RPSP.2018.170.

10. Silva FP, Silva EC, Ferreira AL, Frazão IS. Patient safety: within the reach of the homeless? Rev Bras Enferm [Internet]. 2020;73(5):e20190114. Disponível em: http://dx.doi.org/10.1590/0034-7167-2019-0114.

11. Bezerra WC, Firmino GCS, Javarrotti ES, Melo JVM, Calheiros PFF, Silva RGLB. O cotidiano de pessoas em situação de rua em Maceió-AL: rupturas, sociabilidades, desejos e possibilidades de intervenção da terapia ocupacional. Cad Ter Ocup da UFSCar [Internet]. 2015;23(2):335-46. Disponível em: http://dx.doi.org/10.4322/0104-4931.ctoA00541.

12. Silva MLL. Trabalho e população em situação de rua no Brasil. São Paulo: Cortez; 2009.

13. Hallais JAS, Barros NF. Consultório na rua: visibilidades, invisibilidades e hipervisibilidade. Cad. Saúde Pública [Internet]. 2015;31(7):1497-1504. Disponível em: https://doi.org/10.1590/0102-311X00143114.

14. Abreu D, Oliveira WF. Atenção à saúde da população em situação de rua: um desafio para o Consultório na Rua e para o Sistema Único de Saúde. Cad Saude Publica [Internet]. 2017;33(2):e00196916. Disponível em: https://doi.org/10.1590/0102-311x00196916.

15. Brasil. Ministério do Desenvolvimento e Combate à Fome. Rua: aprendendo a contar. Pesquisa nacional sobre a população em situação de Rua. Brasília, 2009.

16. Oliveira DM, Expedito AC, Aleixo MT, Carneiro NS, Jesus MCP, Merighi MAB. Needs, expectations and care production of people in street situation. Rev Bras Enferm [Internet]. 2018;71:2689-97. Disponível em: http://dx.doi.org/10.1590/0034-7167-2017-0612.

17. Cervieri NB, Uliana $\mathrm{CH}$, Aratani N, Fiorin PM, Giacon BCC. O acesso aos serviços de saúde na perspectiva de pessoas em situação de rua. SMAD Rev Eletrônica Saúde Ment Álcool e Drog [Internet]. 2019;15(4):1-8. Disponível em: http://dx.doi.org/10.11606/issn.18066976.smad.2019.151229.

18. Santana JP, Raffaelli M, Koller SH, Morais NA. "Vocês me encontram em qualquer lugar": realizando pesquisa longitudinal com adolescentes em situação de rua. Psico [Internet]. 2018;49(1):31-42. Disponível em: https://doi.org/10.15448/1980-8623.2018.1.25802.

19. Cunha JG, Garcia A, Silva TH. Novos Arranjos: lançando um olhar sobre os relacionamentos interpessoais de pessoas em situação de rua. Gerais, Rev Interinst Psicol [Internet]. 2017;10(1):95-108. Disponível em: http://pepsic.bvsalud.org/pdf/gerais/v10n1/10.pdf. 
20. Castel R. Da indigência à exclusão, a desfiliação, precariedade do trabalho e vulnerabilidade relacional. In: Lancetti A. Saúde e loucura. São Paulo: HUCITEC; 1993. p. 21-47.

21. Zandomingo MNP, Oliveira JF, Silva DO, Porcino C, Suto CSS, Oliveira DS. Poverty, hunger, and abandonment: representations of the nursing team about homeless persons. Rev Bras Enferm [Internet]. 2020;73(1):e20190338. Disponível em: http://dx.doi.org/10.1590/0034-7167-2019-0338.
22. Lawall VFAA, Francisco FB, Nivaldo CJ. As vivências na rua que interferem na saúde: perspectiva da população em situação de rua. Saúde debate [Internet]. 2020; 44(124):182-192. Disponível em: http://dx.doi.org/10.1590/0103-1104202012413.

23. Biscotto $P R$, Jesus MCP, Silva MH, Oliveira DM, Merighi $M A B$. Understanding of the life experience of homeless women. Rev da Esc Enferm [Internet]. 2016;50(5):74955. Disponível em: https://doi.org/10.1590/s0080623420160000600006 . 
Conflito de Interesses: não há.

Fonte de fomento: não há.

Aprovação do comitê de ética em pesquisa: Parecer n 2.737.153 e CAEE n 90815118.5.0000.5011.

Registro dos ensaios clínicos em base de acesso público: não se aplica.

Autor Correspondente:

John Victor dos Santos Silva

john.setedejulho@gmail.com

Editor:

Prof. Dr. Marcelo Riberto

Recebido: $21 / 10 / 2020$

Aprovado: 09/04/2021 